\title{
PROGRAMA ADOTE O VERDE \\ Parcerias de sucesso em belo horizonte, para a melhoria das áreas verdes públicas do município ${ }^{(1)}$
}

\author{
MARIZA RIZCK MAGALHÃES (2)
}

O Programa Adote o Verde é um programa criado pela Secretaria Municipal de Meio Ambiente de Belo Horizonte, sendo voltado para o estabelecimento de parcerias com a sociedade e objetivando a melhoria e a manutenção de praças, parques, canteiros centrais de avenidas e outras áreas verdes públicas do Município, Gera, com isso, inúmeros benefícios para o Município, dentre os quais citamos a geração de melhores espaços para a prática do lazer e da convivência humana, o embelezamento da cidade, a melhoria da qualidade de vida da população, a conscientização da população acerca da importância das áreas verdes para a qualidade de vida urbana, fomentando a noção de responsabilidade solidária entre o Poder Público e a coletividade, no que toca à preservação de tais áreas, a promoção e o incentivo ao exercício da cidadania e de boas práticas ambientais e a redução de encargos financeiros do Município.

O programa surgiu, formalmente, em 1991, através do Decreto Municipal n 6.992, de 10/10/91, que estabelecia "procedimentos para a implantação ou manutenção de áreas verdes públicas por entidades jurídicas, sem ônus para o Município", embora não tivesse recebido, à época, a denominação oficial de "Programa Adote o Verde", somente oficializada, bem mais tarde, através do Decreto Municipal $n^{\circ} 11.484$, de 15/10/03, que estabelecia "normas e procedimentos para parcerias entre o Poder Publico e a sociedade, no que concerne à adoção de áreas verdes públicas", a iniciativa já era conhecida, desde o seu surgimento, como "adoção de área verde". Por outro lado, embora uma das primeiras adoções de áreas verdes formalmente registradas em Belo Horizonte tenha sido exatamente a da Praça da Liberdade, vigente até hoje e celebrada, à época, pela empresa Minerações Brasileiras Reunidas - MBR (hoje, encampada pela empresa Vale), cuja formalização é coincidente com a época da publicação do primeiro decreto acima citado, é possível haverem ocorrido, anteriormente à publicação do referido decreto, outras iniciativas similares, mesmo que informais. Vale ressaltar ser o Programa Adote o Verde regido, hoje, pelo Decreto Municipal $n^{\circ} 14.708$, de 14/12/11, que revogou o anterior (o de $\mathrm{n}^{\circ} 11.484$ ) e introduziu as seguintes inovações aos procedimentos estabelecidos para as adoções de áreas verdes: possibilidade de chamamento público e de definição de grupos de áreas a serem adotadas conjuntamente e possibilidade de estabelecimento de parcerias adicionais pelo adotante.

O número de áreas adotadas em Belo Horizonte vem sendo mantido, já há algum tempo, na média de cerca de 400 áreas, simultaneamente. Este é um dado bastante dinâmico e variável, uma vez serem passíveis de ocorrer, a um mesmo tempo, a celebração de novos convênios, assim como o encerramento ou a renovação de outros, em quantitativos também bastante variáveis. O que importa, entretanto, é o fato de Belo Horizonte ter podido contar com este expressivo número de áreas adotadas, bastante relevante em termos de contribuição para a cidade. A tabela abaixo, ilustra os quantitativos de áreas adotadas nos últimos 4 anos, tomando-se, por base, levantamentos efetuados nos meses de junho de cada ano, e, no ano de 2013, no mês de março:

\begin{tabular}{|c|c|c|c|c|c|}
\hline $\begin{array}{l}\text { PROGRAMA ADOTE O VERDE } \\
\text { Quantidade áreas adotadas }\end{array}$ & Junho 2009 & Junho 2010 & Junho 2011 & Junho 2012 & Março 2013 \\
\hline Barreiro & 15 & 23 & 13 & 23 & 17 \\
\hline Centro-Sul & 154 & 167 & 150 & 152 & 164 \\
\hline Leste & 6 & 12 & 24 & 18 & 15 \\
\hline Nordeste & 13 & 17 & 10 & 11 & 74 \\
\hline Noroeste & 68 & 157 & 80 & 44 & 26 \\
\hline Norte & $\mathbf{0}$ & 14 & 9 & 21 & 21 \\
\hline Oeste & 47 & 59 & 52 & 17 & 75 \\
\hline Pampulha & 43 & 59 & 30 & 80 & 36 \\
\hline Venda Nova & $\mathbf{0}$ & 2 & 10 & 3 & 8 \\
\hline Fundação de Parques Municipais & 3 & 8 & 5 & 16 & 14 \\
\hline Total & 349 & 518 & 383 & 385 & 450 \\
\hline
\end{tabular}

Fontes: Gerências Regionais de Jardins e Áreas Verdes - GERJAVs e Fundação de Parques Municipais - FPM.

\footnotetext{
(1) Recebido em 10 de maio de 2013 e aceito para publicação em 30 junho de 2013.

(2) Engenheira-Agrônoma - Secretaria Municipal de Meio Ambiente / Prefeitura de Belo Horizonte
} 
Quanto à caracterização do perfil dos adotantes em Belo horizonte, embora a relação entre os números de pessoas físicas ou jurídicas seja bastante dinâmica e variável, tem-se observado, ao longo dos últimos anos, que o percentual de áreas adotadas por pessoas físicas tem permanecido no patamar de $10 \%$ em relação ao total das áreas adotadas, ficando o restante das áreas, ou seja, $90 \%$ do total, por conta de pessoas jurídicas de qualquer natureza (empresas, instituições, ONGs, associações comunitárias, etc.), demonstrando, possivelmente, o grande interesse na divulgação das marcar comercais atreladas a este tipo de iniciativa. De fato, o adotante, quando constituído por pessoa jurídica de qualquer natureza (empresas, instituições, ONGs, associações comunitárias, etc.), ao colaborar com o município, através da parceria estabelecida dentro do Programa Adote o Verde, além de usufruir da nobre possibilidade do exercício da cidadania e de boas práticas ambientais, fazendo elevar seu conceito junto a seus clientes ou público-alvo, usufrui, também, da possibilidade de divulgação de suas marcas atrelada à imagem positiva que estas atividades proporcionam, sendo essa divulgação efetuada através da utilização de placas padronizadas e distribuídas ao longo da própria área adotada, conforme preconizado as regras no Decreto do programa (ver ilustração abaixo).

Quanto à formalização dos convênios de adoção de áreas verdes são eles celebrados, em Belo Horizonte, pelos respectivos órgãos responsáveis pela gestão das áreas, ou seja, pelas Secretarias de Administração Regional Municipal, no caso de praças, jardins ou canteiros centrais de avenidas, ou pela Fundação de Parques Municipais, no caso de parques. Nesse sentido, o interessado em adotar uma determinada área, já previamente identificada ou escolhida, precisa apenas entrar em contato com o respectivo órgão responsável pela área, conforme citado, podendo ainda ser procurada a Secretaria Municipal de Meio Ambiente, no caso de uma não identificação prévia da área a ser adotada. Quanto aos convênios em si, tratamse eles de documentos bastante flexíveis e simples, nos quais são definidas as obrigações de cada parte. Para essas definições, são levadas em consideração a proposta e as características e reais possibilidades do interessado, assim como a conveniência, para a $\mathrm{PBH}$, com relação à aceitação da proposta apresentada. O prazo de vigência de cada convênio também pode variar, sendo o prazo médio atualmente praticado o de dois anos.

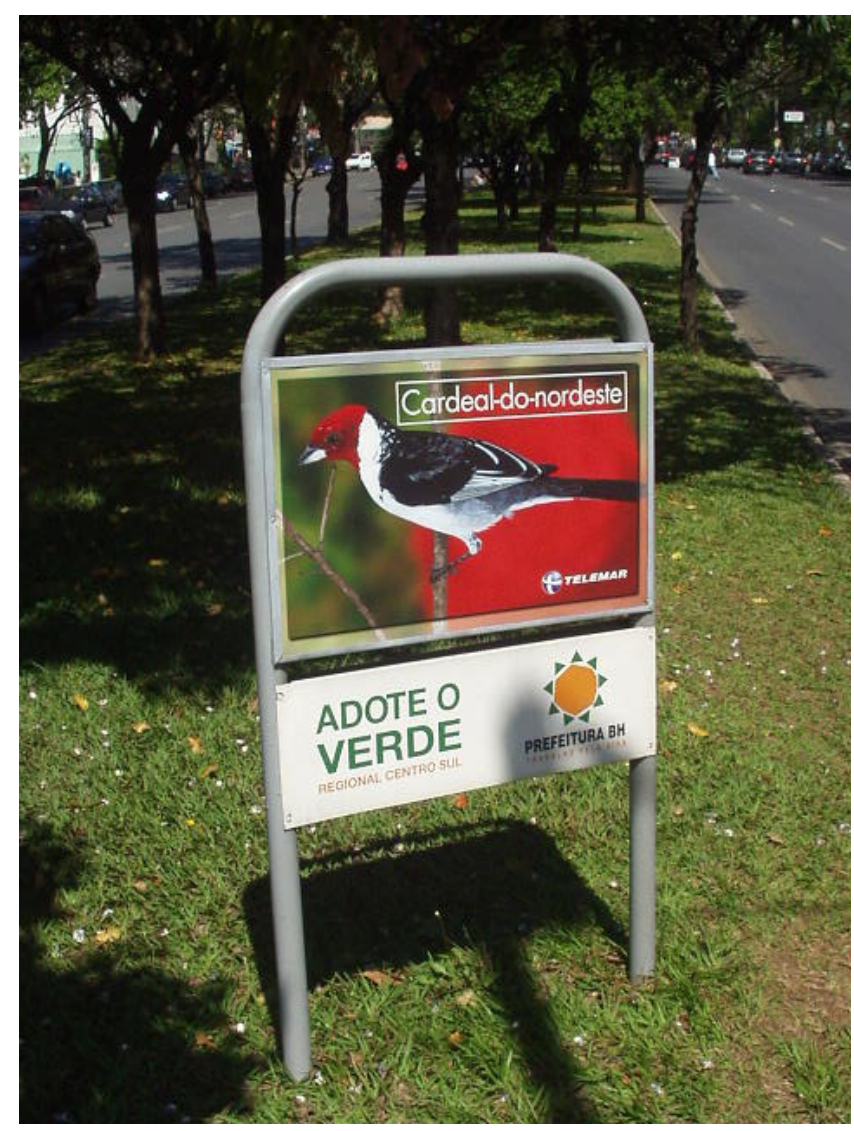

Regras para a utilização das placas:

Áreas de até $1.000 \mathrm{~m} 2: 01$ placa

Áreas de 1.001 a $5.000 \mathrm{~m} 2$ : até 2 placas

Áreas de 5.001 a $10.001 \mathrm{~m} 2$ : até 3 placas

Áreas acima de $10.001 \mathrm{~m} 2$ : até 4 placas

Canteiros centrais de avenidas: 1 placa a cada $150 \mathrm{~m}$

Parques: permitido o uso de placas diferenciadas 